\title{
DESCOLAMENTO DE RETINA MACULAR SEM OUEIXAS VISUAIS: A IMPORTÂNCIA DO EXAME OFTALMOLÓGICO DE ROTINA
}

\author{
MACULA RETINAL DETACHMENT WITHOUT VISUAL COMPLAINTS: THE IMPORTANCE OF ROUTINE OPHTHALMOLOGIC EXAMINATION
}

Sarah Barreto Pinheiro Souza Pinto, Luan Geraldo Ocana de Oliveira, Alipio de Sousa Neto

DOI - 10.5935/2236-5117.2021v58a36

\section{RESUMO}

Objetivo: os autores têm objetivo de relatar um caso de descolamento de retina de apresentação atípica com potencial desfecho visual desfavorável detectado através de um exame de rotina.

Método: relato de caso e revisão de literatura.

Resultado: WBP, 42 anos, feminino procurou oftalmologista para exame de rotina sem queixas visuais. Exame físico: acuidade visual com correção 20/20 em ambos os olhos. Avaliação fundoscópica: descolamento de retina rematogênico na topografia macular à $1 \mathrm{~mm}$ da fóvea. Paciente foi submetida à introflexao escleral e endofotocoagulação a laser. Os procedimentos foram bem sucedidos, sem complicações pós-operatórias. No momento, segue em acompanhamento ambulatorial anual sem outras queixas oftalmológicas.

Conclusão: em suma, este caso evidencia a importância da avaliação oftalmológica de rotina para diagnosticar e intervir precocemente em patológicas oculares graves e silenciosas, a fim de proporcionar melhor prognóstico visual aos pacientes.

Palavras-chave: Descolamento Retiniano. Macula Lutea. Técnicas de Diagnóstico Oftalmológico. Diagnóstico Precoce

\section{ABSTRACT}

Objective: The authors aim to report a case of retinal detachment of atypical presentation with potential unfavorable visual outcome detected through a routine examination.

\section{Method: Case report and literature review.}

Result: WBP, 42 years old, female sought ophthalmologist for routine examination without visual complaints. Physical examination: visual acuity with correction 20/20 in both eyes. Fundoscopic evaluation: rematogenic retinal detachment in the macular topography at $1 \mathrm{~mm}$ of the photol. The patient underwent scleal introflexation and laser
Sarah Barreto Pinheiro Souza Pinto-Centro Universitário do Planalto Central
Apparecido dos Santos (UNICEPLAC), Acadêmica de medicina. Curso de graduação em medicina - Brasília - Distrito Federal - Brasil.

Luan Geraldo Ocana de Oliveira - Unidade de Oftalmologia do Instituto Hospital de Base (IHB), Médico residente - Brasília - Distrito Federal - Brasil.

Alipio de Sousa Neto - Instituto de Cirurgia Ocular de Brasília (ICOB), Médico oftalmologista especialista em retina e vítreo - Brasília - Distrito Federal - Brasil.

Correspondência: Sarah Barreto Pinheiro Souza Pinto. Rua 19, Lote 14, Apt. 601, Sul (Águas Claras), Brasília, DF, Brasil. CEP: 71940-720

Internet: barreto938@gmail.com

Conflito de interesses: não existem conflitos de interesse.

endophotocoagulation. The procedures were successful, without postoperative complications. At the moment, he is under annual outpatient follow-up without other ophthalmologic complaints.

Conclusion: in the meantime, this case highlights the importance of routine ophthalmologic evaluation to diagnose and intervene early in severe and silent eye pathologics, in order to provide better visual prognosis to patients.

Keywords: Retinal Detachment. Macula Lutea. Diagnostic Techniques, Ophthalmological. Early Diagnosis

\section{INTRODUÇÃO}

A retina é uma membrana formada por multicamadas de neurônios aderida ao epitélio pigmentar da retina (EPR) e à coróide, responsável pela sua oxigenação. Sua função é converter a energia luminosa em impulsos nervosos que são transmitidos ao córtex visual. 0 descolamento de retina regmatogênico (DRR) é causado pela passagem de fluido proveniente da cavidade vítrea através de uma ruptura da retina no espaço entre sua camada 
neurossensorial e o EPR ${ }^{1}$. Esse evento é responsável por gerar isquemia e degeneração dos fotorreceptores ${ }^{2}$. Em consequência disso, pode haver perda importante e potencialmente irreversível da acuidade visual, caso não haja detecção e intervenção precoces. A incidência anual de DRR foi relatada em 12 casos a cada 100.000 pessoas e a maior parte dos casos ocorre em pessoas entre 40 e 70 anos de idade ${ }^{3}$. As taxas de incidência de descolamento não traumático são similares entre ambos os sexos, no entanto, existe uma preponderância pelo sexo feminino, devido as mulheres representarem maior parte na população mundial ${ }^{4}$. 0 presente estudo tem o objetivo de relatar um caso de DR de apresentação atípica com potencial prognóstico visual desfavorável detectado em um exame de rotina, e realizar uma breve revisão sobre o tópico.

\section{RELATO DE CASO}

Paciente WBP, 42 anos, sexo feminino, casada, dona de casa, natural de Redenção - CE e procedente de Brasília - DF procurou oftalmologista para exame de rotina sem queixas visuais. À história médica pregressa (HMP), paciente sem histórico de comorbidades e uso de medicações de forma continua. Em relação aos antecedentes oculares progressos (AOP), não há histórico de traumas, intervenções ou cirurgias oculares. No que diz respeito aos antecedentes oculares familiares (AOF), possui irmã com miopia e histórico de DR e pai operado de catarata, segundo informações coletadas. Ao exame físico: acuidade visual com correção (ACV c/c) de 20/20 em olho direito (OD) e 20/20 em olho esquerdo (OE). Biomicroscopia normal em ambos os olhos (AO). À avaliação fundoscópica de $\mathrm{AO}$ : vítreos transparentes. Papilas com escavações fisiológicas, de coloração normal, com bordas bem definidas. Mácula OD: proliferação vitreorretiniana (PVR) inferior à fóvea. OE: brilho e aspecto anatômico habitual. Vasos com calibre e trajeto preservados. Ausência de cruzamentos arteriovenosos patológicos. Coriorretinianas OD: descolamento de retina em quadrante inferior margeando a fóvea com linha de demarcação (figura 1). OE: aplicada com periferias íntegras. Em avaliação complementar, tomografia de coerência óptica (OCT) sinaliza OD: ausência de tração vítreo retiniana detectável. Superfície retiniana regular. Umbus foveal presente, porém com fluido subretiniano junto a borda foveal. Presença de cistos intra-retinianos indicando a cronicidade do quadro de descolamento de retina inferior, Espessura central 312 micra. Epitelio pigmentar regular (Figura 2). OE: normal. Diante da situação clínica, foram feitos com urgência, retinopexia com introflexão escleral e endofotocoagulação trauma e histórico pessoal ou familiar de DR ${ }^{5,6}$. Em acordo com a literatura, o estudo traz uma paciente de 42 anos de idade, do sexo feminino e com história familiar de DR, porém sem histórico de miopia, cirurgias oculares previas e trauma. No que diz respeito à sintomatologia, cerca de metade dos indivíduos apresentam flashes luminosos

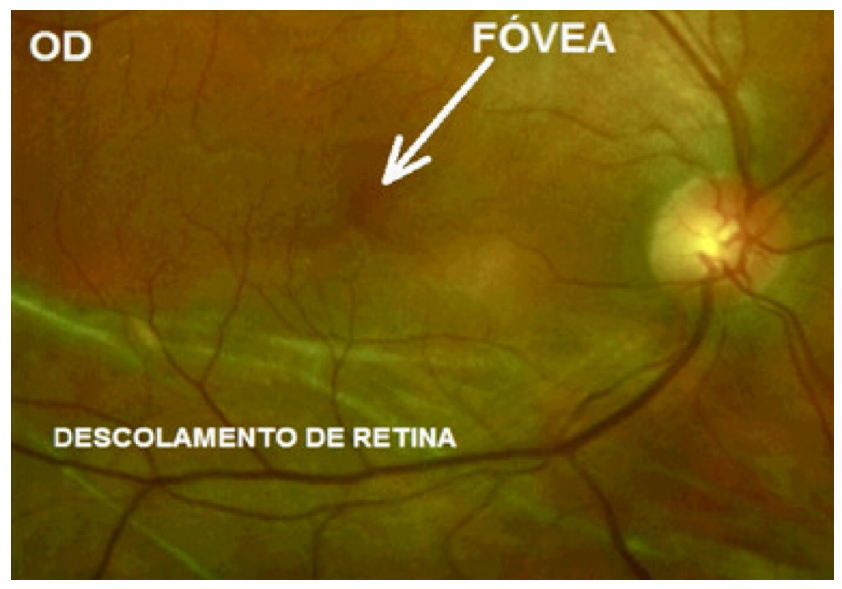

Figura 1. Avaliação fundoscópica OD evidencia descolamento de retina em topografia macular margeando a fóvea com linha de demarcação.

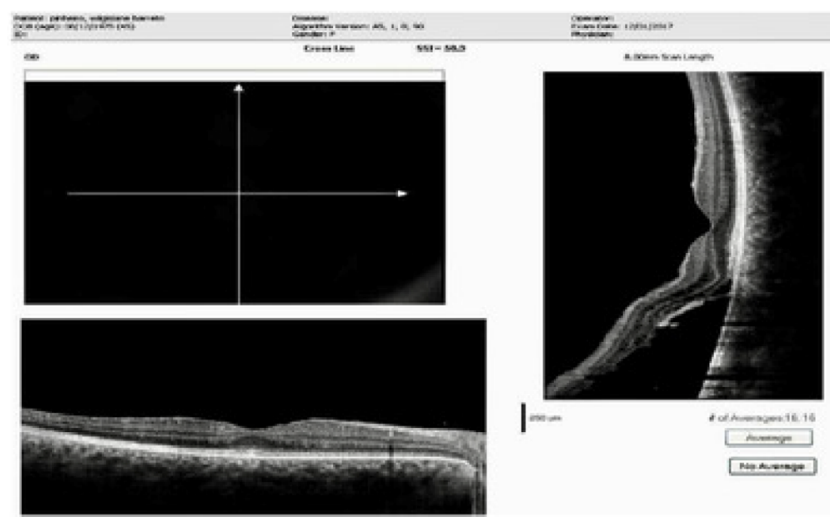

Figura 2. OCT OD mostra fluido subretiniano junto à borda foveal.

à laser. Os procedimentos cirúrgicos foram bem sucedidos, com ótima introflexão, retina reaplicada, laser bem pigmentado e sem complicações ao $50^{\circ}$ dia pós-operatório. No momento, paciente segue em acompanhamento ambulatorial anual, com ótimo desfecho pós-operatório e sem demais queixas visuais.

\section{DISCUSSÃO}

A maior parte dos casos de DR são observados em indivíduos entre os 40-70 anos de idade, sendo o sexo feminino predominantemente afetado ${ }^{3,4}$. Entre os fatores de risco sabidamente predisponentes à essa patologia, destacam-se miopia, cirurgias oculares, 
ou floateres/"moscas volantes" ${ }^{1}$. Frequentemente é descrito pelos doentes uma "cortina escura" que restringe o campo visual periférico e progride no sentido central da visão dentro de horas a semanas ${ }^{7}$. Entre os principais sintomas, nenhum foi relatado. Ao exame clínico, a ACV pode ser normal em casos de DRR se a área macular não tiver sido acometida 3 . Neste caso, a ACV c/c documentada foi 20/20 em AO a despeito do comprometimento macular em OD. Durante a biomicroscopia, é possível observar a presença de células vítreas pigmentadas por de trás do cristalino ${ }^{3}$. Esse achado não esteve presente ao exame clínico. 0 reconhecimento do DRR à avaliação fundoscópica inclui retina opaca, elevada e ondulada, de configuração convexa e que ondula livremente acompanhando os movimentos oculares ${ }^{1}$. Neste estudo, essa alteração foi observada em OD. Além disso, o mesmo exame demonstrou DR na área macular à $1 \mathrm{~mm}$ da fóvea. Mácula é a região central da retina, tem aproximadamente 5,5 $\mathrm{mm}$ de diâmetro e sua estrutura central, fóvea, mede 1,5 $\mathrm{mm}$ e ambas são responsáveis pelo campo visual central e pela elevada acuidade e coloração visual ${ }^{1}$. Uma vez que a área macular é acometida pelo DR, o campo visual central e a acuidade podem ser notadamente afetados ${ }^{3}$. No presente caso, em contraposição à literatura, mesmo com comprometimento da mácula, não constatou-se ao exameperdadecamponemtampouco deacuidadevisual. Desse modo, torna-se evidente a gravidade e o caráter atípico do caso em relato, devido ao comprometimento macular e à ausência de sintomatologia visual típica.

Em caso de DRR agudo e sintomático sem que a mácula seja acometida, é mandatória intervenção de urgência (dentro de $24 \mathrm{~h}$ ) a fim de evitar progressão central e perda da visão ${ }^{1}$. Por outro lado, em casos assintomáticos com descolamento crônico e linha de demarcação pigmentada, situação clínica em questão, o tratamento pode ser adiado ou consistir apenas no monitoramento rigoroso do DR a cada 3 meses $^{1}$. Tendo em vista a área nobre acometida, optou-se por intervenção cirúrgica. A reaplicação da retina após o DRR é obtida através do bloqueio cirúrgico da ruptura retiniana, retinopexia ${ }^{8}$. Essa cirurgia inclui técnicas epi-esclerais (introflexao escleral) ou vítreas (cirurgia pneumática e vitrectomia), ambas comumente associadas ${ }^{8}$. Após esse procedimento é necessário que se forme uma cicatriz entre a retina e a coróide para que ela permaneça aderida, obtida por meio de crioterapia, diatermia ou endofotocoagulação à laser $^{8}$. Na paciente em particular foi realizada retinopexia por meio de introflexao escleral e endofotocoagulação. Os índices de sucesso das técnicas de retinopexia pneumática, introflexão escleral e vitrectomia são estimados, respectivamente, em $77 \%$, $89 \%$ e $92 \%{ }^{4}$. No presente estudo, os procedimentos cirúrgicos foram bem sucedidos e sem quaisquer complicações pós-operatórias, com excelente introflexão, retina reaplicada e laser bem pigmentado. Paciente segue em acompanhamento ambulatorial anual para exame de rotina, sem outras queixas visuais.

\section{CONCLUSÃO}

A paciente em questão poderia ter tido outro desfecho, culminado em perda definitiva da visão central, caso não tivesse visitado o oftalmologista para exame de rotina. Diante do presente caso, nota-se a necessidade do exame oftalmológico de rotina para o diagnóstico e intervenção em tempo hábil tratando-se de patologias oculares esporadicamente silenciosas e de prognóstico visual reservado a depender do tempo de evolução.

\section{REFERÊNCIAS}

1. Retina and Vitreous. American Academy of Ophthalmology AAO. 2019.

2. Yang L, Bula D, Arroyo JG, Chen DF. Preventing retinal detachment-associated photoreceptor cell loss in Baxdeficient mice. Invest Ophthalmol Vis Sci 2004; 45:648.

3. Colucciello M. Rhegmatogenous retinal detachment. Phys Sportsmed. 2009 Jun;37(2):59- 65. doi: 10.3810/ psm.2009.06.1710. PMID: 20048510.

4. Kwon OW, Song JH, Roh MI. Retinal Detachment and Proliferative Vitreoretinopathy. Dev Ophthalmol. 2016;55:154-62. doi: 10.1159/000438972. Epub 2015 Oct 26. PMID: 26501375.

5. GoSL, HoyngCB, KlaverCC. Genetic risk of rhegmatogenous retinal detachment: a familial aggregation study. Arch Ophthalmol 2005; 123:1237.

6. Risk factors for idiopathic rhegmatogenous retinal detachment. The Eye Disease Case- Control Study Group. Am J Epidemiol 1993; 137:749.

7. Kwok JM, Yu CW, Christakis PG. Retinal detachment. CMAJ. 2020 Mar 23;192(12):E312. doi: 10.1503/cmaj.191337. PMID: 32392514; PMCID: PMC7101175.

8. Maia Junior, Otacílio de Oliveira et al. Descolamento regmatogênico de retina: avaliação pós-operatória da mácula. Arq. Bras. Oftalmol., São Paulo, v. 70, n. 6, p. 9961000, dez. 2007. 